\title{
Eine litauische Alternative für die ganze Rus'? Die Ostpolitik der litauischen Herrscher im ausgehenden Mittelalter: Ansprüche und Wirklichkeit
}

\section{Lithuanian alternative for the whole Rus? Eastern policy of the Lithuanian rulers in the late Middle Ages: Claims and reality}

Полехов Сергей Владимирович / sergey.polekhov@gmail.com

Школа актуальных гуманитарных исследований Института общественных наук Российской академии народного хозяйства и государственной службы (Schule für aktuelle geisteswissenschaftliche Forschungen des Instituts für Gesellschaftswissenschaften der Russischen Akademie der Volkswirtschaft und des Staatsdienstes), MockBa, RU

\begin{abstract}
The aim of the article is to analyze the widely spread idea that the late medieval Grand Duchy of Lithuania could unite the whole Rus' and pose an alternative to Moscow. It is shown that the Lithuanian rulers didn't lay such claims; the attempts to detect them in their statements made in 1358 and (allegedly) in 1399 are nothing but misinterpretations. It is also shown that Algirdas, Jogaila and Vytautas had no real chances to subjugate the Duchy of Moscow and its allies and vassals, both as the result of their military expeditions (1368-1372, 1406-1408) and due to the matrimonial union (1383/84).
\end{abstract}

\section{Keywords}

Grand Duchy of Lithuania; Lithuanian Expansion into the Rus'; International Relations in the Late Middle Ages; Algirdas; Vytautas

\footnotetext{
Ich bedanke mich bei Dr. Roman Hautala (Oulu), Dr. hab. Elena Konyavskaya (Moskau), Dr. Olena Rusyna (Kiew), Prof. Iskra Schwarcz (Wien), Prof. Adam Szweda (Toruń) und Dr. Andrey Vinogradov (Moskau) für die wertvollen Literaturhinweise, Sprachkonsultationen und Kopien einiger Aufsätze, die mir sonst unzugänglich wären.

Bei der Zitierung russischer Texte werden Abkürzungen stillschweigend aufgelöst; von den nicht mehr gebrauchten Buchstaben wird nur "B" beibehalten.
} 


\section{Einführung: Die politisch-territorialen Veränderungen in der Rus' vom 13. bis ins 15. Jahrhundert}

Kurz nach dem mongolischen Einfall in die Rus', wahrscheinlich im Jahre 1238, schrieb der Verfasser eines Schriftdenkmals, das unter dem Titel „Klage über den Untergang des russischen Landes“ („Слово о погибели Русской земли“) bekannt ist, mit Nostalgie über die vergangene Epoche: „Die Litauer krochen aus den Sümpfen nicht heraus. “1 $\mathrm{Zu}$ jener Zeit bestand die Rus' aus einer Reihe der Fürstentümer und Länder, von denen einige die mongolische Oberherrschaft bald anerkannten. Zwei Jahrhunderte später, im Jahre 1449, teilten der Großfürst Kasimir Jagiellone von Litauen (1440-1492, seit 1447 zugleich König von Polen) und der Großfürst von Moskau Vasilij II. (der Blinde, 1425-1462) die Machtbereiche in Osteuropa auf. Unter anderem gab der litauische Herrscher jegliche Ansprüche auf Groß-Novgorod und Pleskau auf, und der Moskauer Großfürst erkannte das Bündnis zwischen den Großfürstentümern Tveŕ und Litauen an. ${ }^{2}$ Somit war die ganze Rus' im wesentlichen zwischen diesen zwei Herrschern geteilt. Beide Quellen markieren symbolisch den Anfangs- und den Endpunkt der territorialen Expansion Litauens.

Die politischen Veränderungen in der Rus' zwischen dem 13. und dem 15. Jahrhundert wurden von den Zeitgenossen, Ideologen, späteren Publizisten und Forschern verschieden wahrgenommen. Wohl kurz nach dem Tod von Dmitrij Donskoj (1353-1389) nannte der Verfasser der ihm gewidmeten Lobrede seinen Großvater Ivan Kalita (13251340) einen „Sammler des russischen Landes “;” diese schöne Auffassung bürgerte sich auch in der Forschung ein. Die sowjetischen Historiker schrieben ganz teleologisch über die Entstehung des „zentralisierten Russischen Staates“, die vom Großfürstentum Litauen nur behindert wurde. Jetzt ist es üblicher, von der Aufteilung und späteren Neuaufteilung der Rus' zu sprechen. ${ }^{4}$

Natürlich kommt die Frage nach Alternativen zu dieser Entwicklung auf. In der Forschungsliteratur und besonders in der populären Literatur wird das Großfürstentum Litauen manchmal als ein alternatives Zentrum des „Sammelns des russischen Landes“ betrachtet; dieser Vorgang wird als ein Ringen/Rivalität Litauens mit Moskau dargestellt. ${ }^{5}$

1 [...] а Литва изб болота на свътб не выникываху (Бегунов, Юрий К.: Памятник русской литературъ ХІІІ века “Слово о погибели Русской земли”. Москва - Ленинград 1965, S. 154). Zur Datierung: Горский, Антон А.: Проблемы изучения “Слова о погибели Рускыя земли» (К 750-летию со времени написания). Труды отдела древнерусской литературы 43. Ленинград 1990, S. 18-38.

2 Духовные и договорные грамоты великих и удельных князей XIV-XVI вв. (= ДДГ). Подг. Лев В. Черепнин. Москва - Ленинград 1950, Nr. 53, S. 160-163.

3 Полное собрание русских летописей (= ПСРЛ) 4. Вып. 1. Москва 2000, S. 351: [...] внукъ же бысть православнаго князя Ивана Даниловича, събирателя Рускои земли.

4 Горский, Антон А.: От земель к великим княжениям: «примысль» русских князей второй половины ХІІІ - XV в. Москва 2010. Vgl. zur Kritik der Konzeption der „Sammlung der russischen Länder“: Горский, Антон А.: Средневековая Русъ. О чем говорят источники. Москва 2016, S. 170-181; Кром, Михаил М.: Рождение государства. Московская Русь XV-XVI веков. Москва 2018, S. 9-25.

5 Ловмяньский, Хенрик: Русско-литовские отношения в XIV-XV вв. In: Феодальная Россия во всемирноисторическом процессе. Сборник статей, посвященных Льву Владимировичу Черепнину. Еd. 
Nach einer anderen Auffassung, war das Großfürstentum Litauen etwas ganz fremdes für die Rus'. Sie wurde beispielweise von dem berühmten sowjetischen Historiker Vladimir Paschuto vertreten und verteidigt, der jedoch in diesem Fall mehr als Ideologe als ein Forscher wirkte. ${ }^{6}$ Mann darf fragen: konnten die litauischen Fürsten wirklich „die ganze Rus'“ unter ihrer Herrschaft vereinigen und in dieser Hinsicht mit Moskau konkurrieren? Und, wenn ja, zu welchem Zeitpunkt?

Zunächst seien die Akteure kurz vorgestellt. In den 40er Jahren des 13. Jahrhunderts entstand das System der mongolischen (und später - der tatarischen) Herrschaft über die Rus', was in der Forschungsliteratur immer noch häufig als das Tatarenjoch bezeichnet wird (interessanterweise nach einer Stelle bei Jan Długosz). ${ }^{7}$ Dieses System bestand hauptsächlich darin, dass die Länder der nord-östlichen und süd-östlichen Rus' dem mongolischen Großkhan und später dem Khan der Goldenen Horde Tribut zahlen sollten; der Khan bestätigte einen Fürsten mit seinem Schreiben - dem Jarliq; ein Fürst sollte den Khan nach seiner Einladung in Karakorum und später in der Horde an der Wolga besuchen; im Falle von Ungehorsam konnte der Khan sein Heer in die Rus' schicken. Die Fürstenthrone waren erblich, mit Ausnahme des Großfürstentums Wladimir, das vom Khan verliehen wurde. Das Großfürstentum Wladimir stand an der Spitze in der Hierarchie der nord-östlichen russischen Fürstentümer. Ihm war auch Groß-Novgorod unterstellt, eine riesige Stadtrepublik; das benachbarte und ursprünglich den Novgoroder Fürsten unterstellte Pleskau gewann allmählich immer mehr an Selbständigkeit. Erst in der 2. Hälfte des 13. Jahrhunderts entstand im Nord-Osten das Fürstentum Moskau, dessen Fürsten allmählich anfingen, ihr Territorium zu erweitern. ${ }^{8}$ Die Wege dieser Erweiterungen waren verschieden - vor allem nicht Eroberungen, sondern in erster Linie dynastische Ehen, Käufe und die Beerbung von den ausgestorbenen Fürstenlinien mit den Genehmigungen des Khans. ${ }^{9}$ Zur Stärkung des Fürstentums Moskau trugen die Siege seiner Fürsten über die Herrscher von Tveŕ bei: erstmals über Aleksandr Michajlovič (1326-1327, 1337-1339), als Ivan Kalita sich an der Niederwerfung des antitatarischen Aufstandes 1327 aktiv beteiligte; danach über seinen Sohn Michail

Владимир Т. Пашуто. Москва 1972, S. 269-275; Греков, Игорь Б.: Восточная Европа и упадок Золотой Орды (на рубеже XIV-XV веков). Москва 1975; Думин, Станислав В.: Другая Русъ (Великое княжество Литовское и Русское). In: История Отечества: люди, идеи, решения. Очерки истории России IX начала XX в. Москва 1991, S. 76-126; Бушков, Александр А. - Буровский, Андрей М.: Россия, которой не было-2. Русская Атлантида. Красноярск - Москва 2003; КАРАцуБА, Ирина В. - Курукин, Игорь В. - Соколов, Никита П.: Выбирая свою историю. «Развилки» на пути России: от Рюриковичей до олигархов. Москва 2005, S. 67-84.

6 Пашуто, Владимир Т.: Возрождение Великороссии и судъбы восточных славян. In: Пашуто, Владимир Т. - Флоря, Борис Н. - Хорошкевич, Анна Л.: Древнерусское наследие и исторические судьбы восточного славянства. Москва 1982, S. 7-68, besonders S. 28.

7 Deugosz, Jan: Annales seu Cronicae incliti Regni Poloniae. Lib. XII (1462-1480). Cracoviae 2005, S. 442-443.

8 Кучкин, Владимир А.: Роль Москвы в политическом развитии Северо-Восточной Руси конча ХIII в. In: Новое о прошлом нашей страны. Памяти академика М. Н. Тихомирова. Москва 1967, S. 54-64; Idem: Первый московский князь Даниил Александрович. Древнейшие государства Восточной Европы. 2005 год. Рюриковичи и российская государственность. Москва 2008, S. 294-318.

9 Ausführlich dazu: Горский, А. А.: От земель к великим княжениям, passim. 
Aleksandrovič (1365-1399) infolge der Auseinandersetzungen 1367-1375. ${ }^{10}$ Im Ergebnis erhielten die Moskauer Fürsten dauerhaft den Jarliq für das Großfürstentum Wladimir, sodass Dmitrij Donskoj ihn seinem Sohn Vasilij (I., 1389-1425) im Testament vermachte. Seit der Regierungszeit Dmitrijs blieb das Großfürstentum Wladimir in den Händen der Moskauer Herrscher. ${ }^{11}$

Der Aufstieg Litauens begann wohl am Ende des 12. Jahrhunderts, als die ersten Raubzüge der Litauer bezeugt sind. Ihr wichtiges Ziel waren die russischen Länder. Aus dem 13. Jahrhundert stammen die ersten Territorialerwerbungen in der von den Kriegen der Riurikiden und dem mongolischen Einfall geschwächten Rus' - vor allem Novgorodok, Slonim und Volkovysk, die später unter dem Namen die Schwarze Rus' bekannt waren und im 15. Jahrhundert sogar zu Litauen im eigenen Sinne zählten. ${ }^{12}$ Schon in den 70er Jahren des 13. Jahrhunderts gehörte Grodno zur Herrschaft der Litauer. ${ }^{13}$ Unter den Großfürsten Witen (Vytenis, 1296(?)-1316) und Gedimin (Gediminas, 1316-1341) kamen weitere wichtige Zentren unter die Hoheit der litauischen Fürsten - die Handelsstädte Polozk und Witebsk sowie Brest und wahrscheinlich Kiew. ${ }^{14}$ Die Aktivisierung der litauischen Ostpolitik ist mit dem Namen des Großfürsten Olgerd (Algirdas, 1345-1377) verbunden, der sich auch mit Polen und Ungarn in das Ringen um Wolhynien verwikkelte. ${ }^{15}$ Auch erst damals stellte es sich heraus, dass die Moskauer Fürsten besonders aktiv die russischen Länder angliedern, obwohl schon Gedimin und sogar seine Vorfah-

10 Klug, Ekkehard: Das Fürstentum Tveŕ (1247-1485). Aufstieg, Selbstbehauptung und Niedergang. Forschungen zur osteuropäischen Geschichte 37, 1985, S. 7-355; Горский, Антон А.: Москва и Орда. Москва 2003; Кучкин, Владимир А.: Договорные грамоть московских князей XIV века. Внешнеполитические договоры. Москва 2003.

11 дЛГ, Nr. 12, S. 33.

12 БАРАНАускас, Томас: Новогрудок в ХІІІ веке: история и миф. In: Castrum, urbis et bellum. Баранавічы 2002, S. 29-44; Дувонис, Артурас: Две модели литовской экспансии на Руси (ХIII - начало XIV века). Овладение Полочком и Новогрудком. Исторический вестник 7 (154): Литва, Русь и Польша XIII-XVI вв. Москва 2014, S. 54-85.

13 Dubonis, Artūras: Traidenis. Monarcho valdžios atkūrimas Lietuvoje. 1268-1282. Vilnius 2009, S. 163; TĘGOWSKI, Jan: Rola Grodna w sktadzie Wielkiego Księstwa Litewskiego w XIV i poczatkach XV wieku. In: Гарадзенскі палімпсест. 2012. Людзі даўняй Гародні. XV-XX ст. Гродна 2013, S. 60-61; Лгцкевгч, Алег: Гародня $i$ Гарадзенскі рэгіён у другой палове XIII - XIV ст.: назва і межы. Ibid., S. 10-59; Idem: Гародня і Гарадзенскі рэгіён уу другой палове ХIII - XIV ст. Сухапутныя і водныя камунікаиыі, населеныя пункты, этнаканфесійны склад і міграчьі насельніитва. Arche 11, 2014, S. 8-60.

14 ВАронгн, Васіль А.: Падзеі 1307 года у Полачку: спроба крытычнага разбору. Гісторыя і археалогія Полацка і Полацкай зямлі. Матәрыялы V Міжнароднай навуковай канферэнцыі (24-25 кастрычніка 2007 г.). Полацк 2009, S. 30-40; Воронин, Василий А.: Княжение Олъгерда в Витебске. Ukraina Lituanica. Студії з історії Великого князівства Литовського. Т. 2. Київ 2013, S. 21-38. Dass auch Kiew unter der Oberhoheit des litauischen Herrschers stand, zeugt die Erzählung der ersten Novgoroder Chronik über die Ereignisse im Jahre 1331 (siehe unten Anm. 31). Der Versuch von Olena Rusyna, den Kiewer Fürsten Fjodor vom gleichnamigen, in einer anderen Quelle erwähnten Bruder Gedimins zu „trennen“, scheint unüberzeugend zu sein, auch trotz der Richtigkeit ihrer Kritik der Erzählungen über Gedimins Kriegszug nach Kiew (Русина, Олена: Псевдокиӥвські князі XIII-XV cm. In: Eadem: Студії з історії Києва та Київської землі. Київ 2005, S. 38-72, hier S. 46-50).

15 Грушевський, Михайло С.: Iсторія Украӥни-Руси. Т. 4. XIV-XVI віки - відносини полїтичні. Київ 1993, S. 19-63; PAszkiewicz, Henryk: Polityka ruska Kazimierza Wielkiego. Warszawa 1925. 
ren mit den nordöstlichen Riurikiden aktiv zusammenwirkten und mit den Moskauer Herrschern direkt zusammenstießen. ${ }^{16}$ Die letzte große Erwerbung war das Smolensker Land. Nach dem Ringen um Einfluss auf dieses Fürstentum mit langer Tradition einer Staatlichkeit zwischen Moskau und Litauen eroberte Witold (Vytautas, 1392-1430) Smolensk 1395 und nach dessen Abfall 1401 erneut im Jahre 1404 und verleibte das Smolensker Land dem Großfürstentum Litauen ein. Die spätere Ostpolitik Witolds führte trotz des europaweiten Ruhmes seiner Kriege mit Pleskau (1406-1408, 1426), Moskau (1406-1408) und Groß-Novgorod (1428) zu keinen dauerhaften Erfolgen. Es gelang ihm nicht, Groß-Novgorod und Pleskau zu erobern, beiden Stadtrepubliken konnte er lediglich eine Kontribution auferlegen (abgesehen von Gefangenen und der Kriegsbeute; die Nachrichten von den litauischen Fürsten in Novgorod und Pleskau stammen erst aus viel späterer Zeit). Auch der Krieg mit Moskau führte nur zu kleineren Territorialerwerbungen in den östlichen Grenzgebieten des Litauischen Staates. ${ }^{17}$ Witold ist es zwar gelungen, ein günstiges Abkommen mit den Fürsten von den Gebieten an der oberen Oka (Nowossil-Odoew) zu schließen, die Oberhoheit über sie vom Moskauer Großfürsten zu „übernehmen“ und sie während seiner Reise 1427 ihm huldigen zu lassen ${ }^{18}$, jedoch blieben sie weitgehend selbständig. ${ }^{19}$

Obwohl die Quellen über die litauische Expansion höchst fragmentarisch und ziemlich wortkarg sind, kann man auf ihrer Grundlage schon behaupten, dass nicht die Rus', sondern gerade Litauen mit seinen Kriegszügen und Eroberungen eine aktive Rolle in diesem Vorgang spielte. Davon zeugen Quellen verschiedenster Provenienz. Der päpstliche Legat Johann de Plano Carpini bemerkt zu seiner Reise von Wladimir nach Kiew im Winter 1245/1246, er und seine Mitgesandten seien „auf der ganzen Reise fortwährend in Lebensgefahr vonseiten der Luthuaner (Lithauer), die häufig ganz unversehens räuberische Einfälle, soweit sie irgendwie konnten, in das russische Land und besonders in den Gegenden,

16 Dubonis, Artūras: Ties Lietuvos ir Maskvos tarpusavio santykiu ištakomis. In: Tarp istorijos ir būtovès. Studijos prof. Edvardo Gudavičiaus 70-mečiui. Vilnius 1999, S. 55-67.

17 Иванов, Дмитрий И.: Московско-литовские отношения в 20-е годы XV столетия. Средневековая Русь 2, 1999, S. 79-115, БЕспалов, Роман А.: Литовско-московские отношения 1392-1408 годов в связи со смоленской, черниговской и рязанской политикой Витовта и Василия I. Средневековая Русь 12, $2016, \mathrm{~S}$. 129-182; künftig auch Polechov, Sergej: Zwischen Kreuzzügen und Bündnissen: Die Politik des Großfürsten Witolds von Litauen (1392-1430) gegen die östlichen Nachbarn (im Druck).

18 Codex epistolaris Vitoldi, magni ducis Lithuaniae, 1376-1430 (= CEV). Ed. Antoni Prochaska. Cracoviae 1882 , Nr. 1298, S. 779. Die in der Literatur fast übersehene Stelle in diesem Brief Witolds lässt die Chronologie seiner Machterweiterung in dieser Region der Rus' präzisieren: Witold nennt die Fürsten, die sich uns etliche vardt, etliche huwer, etliche itczund begebin habin mit iren landen und luthen - der Ausdruck vardt und huwer (fert und heuer) bedeutet "sowohl im vergangenen als auch in diesem Jahr", also in den Jahren 1426 und 1427 (Grimm, Jacob - Grimm, Wilhelm: Deutsches Wörterbuch 3: E - Forsche. Leipzig 1862 [ND München 1984], Sp. 1547-1548; Ibid. 10: H - Juzen. Leipzig, 1877 [ND München 1984], Sp. 1284-1285). Offensichtlich nutzte dabei Witold die Minderjährigkeit von seinem Enkel, dem neuen Großfürsten von Moskau Vasilij II., aus.

19 Кром, Михаил М.: Меж Русъю и Литвой. Пограничные земли в системе русско-литовских отношений кониа XV - первой трети XVI в. Москва 2019³, S. 43-118; Бяспалай, Раман - ПалеХАй, Сяргей: Гісторыя літоуска-навасількіх дагавораў 1427-1491 гадоў $i$ літоўска-варатынскія граматы 1483 i 1488 гадоў. Беларускі гістарычны агляд 25, 2018, S. 173-227. 
durch die unser Weg führte, machten, und weil der größte Teil der Bewohner Rußlands von den Tataren getötet oder in die Gefangenschaft geschleppt war, hatten sie ihnen gar keinen erfolgreichen Widerstand entgegensetzen können. " ${ }^{20}$ Der Novgoroder Kliment vermachte in seinem Testament (um 1255-1257) einen Teil seines Gutes Andrej, dessen Vater Woin ihn aus dem litauischen Gefängnis befreite. ${ }^{21}$ Die Kriegszüge der Litauer stellten auch für die Herrscher eine Gefahr dar. An der Jahreswende 1248/49 starb Michail Chorobrit, einer der Fürsten der nord-östlichen Rus', in einem Scharmützel mit den Litauern, ${ }^{22}$ und 1262 töteten sie den masowischen Fürsten Siemowit I. (1247-1262). ${ }^{23}$ Sogar wenn ein Territorium anscheinend freiwillig dem Litauischen Staat angegliedert war, erfolgte dies das unter einem starken militärischen Druck, wie das in den Quellen relativ gut beleuchtete Beispiel Witebsk belegt (siehe unten).

Hier sei auf zwei Faktoren hinzuweisen, die zur litauischen Aktivität und zu ihren Erfolgen beitrugen. Der erste bestand darin, dass die Plünderungszüge eine wichtige wirtschaftliche Grundlage des frühen Litauischen Staates und seiner führenden Klasse, der Bojaren, war. Die Landesverleihung durch den Großfürsten an die Bojaren für ihren Dienst, besonders aktiv seit der Regierungszeit Witolds, trug dazu bei, dass sie an fernen und gefährlichen Kriegszügen nicht mehr interessiert waren, sondern die wirtschaftliche Entwicklung und Nutzung ihrer Güter bevorzugten. ${ }^{24}$ Der zweite war die allmähliche Modernisierung der staatlichen und gesellschaftlichen Strukturen - die Litauer wussten es, nicht nur die Ressourcen der geplünderten und angegliederten Länder zu nutzen, sondern auch die „Know-Hows“ von den Nachbarn zu übernehmen und entsprechend Innovationen in der Kriegskunst, Wirtschaft usw. einzuführen. ${ }^{25}$

20 Giovanni di Pian di Carpine: Storia dei Mongoli. Ed. critica del testo latino a cura di E. Menesto. Spoleto 1989, S. 304: [...] ibamus semper sub periculo capitis propter Luthuanos, que sepe insultum faciebant occulte quantum poterant super terram Ruscie, et maxime in locis illis per que debebamus transire. Et quia maior pars hominum Ruscie a Tartaris fuit occisa vel in captivitatem deducta, iccirco eis resistere potenter minime possent. Deutsche Übersetzung zitiert nach Johann de Plano CARPINI: Geschichte der Mongolen und Reisebericht 1245-1247. Übersetzt und erläutert von Dr. Friedrich Risch. Veröffentlichungen des Forschungsinstituts für vergleichende Religionsgeschichte an der Universität Leipzig. II. Reihe. H. 11. Leipzig 1930, S. 219.

21 Грамоть Великого Новгорода и Пскова (= ГВНП). Москва - Ленинград 1949, Nr. 105, S. 162-163. Zur Datierung: Янин, Валентин Л.: Новгородские акты ХII-XV в. Хронологический комментарий. Москва 1991, S. 211-212.

22 Кучкин, В. А.: Роль Москвы, S. 57-58.

23 Petrauskas, Rimvydas: Lietuviai anno Domini 1262: kodel buvo nukirsdintas Mazovijos valdovas Siemovitas? In: Idem: Lietuvos Didžioji Kunigaikštystè. Politika ir visuomenè vèlyvaisiais Viduramžiais. Vilnius 2017, S. 163-177; SzwedA, Adam: Polityka Siemowita I mazowieckiego wobec zakonu krzyżackiego po 1254 roku. Rocznik Grudziądzki 15, 2003, S. 21-37.

24 Łowmiń́ski, Henryk: Uwagi w sprawie podtoża spotecznego i gospodarczego unii jagiellońskiej. In: Idem: Studia nad dziejami Wielkiego Księstwa Litewskiego. Uniwersytet im. Adama Mickiewicza w Poznaniu. Ser. Historia. Nr. 108. Poznań 1983, S. 365-454.

25 NikžEntaitis, Alvydas: Litauen unter den Großfürsten Gedimin (1316-1341) und Olgerd (1345-1377). In: Die „Blüte“ der Staaten des östlichen Europa im 14. Jahrhundert. Deutsches Historisches Institut Warschau. Quellen und Studien. Bd. 14. Wiesbaden 2004, S. 65-76; BARONAs, Darius: Der Kontext der litauischen Kriegskunst des 13. Jahrhunderts und die militärischen Innovationen von der zweiten Hälfte des 14. Jahrhunderts bis zum Beginn des 15. Jahrhunderts. In: Tannenberg - Grunwald - Žalgiris 1410: Krieg und Frieden im späten Mittelalter. Deutsches Historisches Institut Warschau. Quellen und Studien. Bd. 26. Wiesbaden 2012, S. 159-173. 
Häufig wird die Rolle der dynastischen Ehen als ein Mittel der litauischen Expansion betont: nach den Vorstellungen mancher Autoren gingen die Besitzungen der ausgestorbenen fürstlichen Linien in die Macht der litauischen Herrscher über. In der Tat sind nur zwei Beispiele bekannt, die diese Behauptung bestätigen könnten, beide aus der 1 . Hälfte des 14 Jahrhunderts, - Luzk und Witebsk. Die Geschichte des Fürstentums Luzk ist lediglich aus der ein Jahrhundert später verfassten „Chronik der Großfürsten von Litauen“ bekannt (auch wenn man ihre Bestätigung in der Schenkung des Fürsten Lubart [Liubartas] für den Bischofsstuhl von Luzk sehen kann). ${ }^{26}$ Die Forscher streiten sich darüber, wessen Tochter Lubart heiratete und welche dynastische Rechte er damit erwarb. ${ }^{27}$ In jedem Fall sollte er in dem Krieg um das wolhynische Erbe nach dem Tod von Boleslaw-Jurij II. (um 1323 - 1340) seine Rechte mit Waffen verteidigen und behaupten, was bis zu seinem Tode mehr als vierzig Jahre dauerte. Was das Fürstentum Witebsk angeht, ist Olgerds Ehe mit der Tochter des letzten lokalen Riurikiden wiederum aus einer viel späteren Quelle bekannt. Die zeitgleichen Quellen bezeugen, dass die Litauer schon einige Jahrzehnte vor der Schließung dieser Ehe einen starken militärischen Druck auf das Witebsker Land ausübten. Besonders aufschlussreich ist ein Brief der Rigenser an den Witebsker Fürst Michail Konstantinovič, der eine Liste der Klagen anführt. Aus diesen Klagen erfahren wir, dass die Litauer vor Witebsk (der „Hauptstadt“ des Fürstentums!) lagerten und gefangene Mädchen verkauften. Einige Jahrzehnte später folgte die „freiwillige“ Angliederung des Fürstentums Witebsk an das Großfürstentum Litauen.28

Wie die Forschungen der matrimonialen Politik der Gediminiden zeigen, waren dynastische Ehen nicht als Instrument der territorialen Angliederungen wichtig, sondern zum Schließen von Bündnissen. Ihre Bedeutung war eher kurzfristig, und solche Bündnisse sollte man aufrechterhalten. Es ist nicht zufällig, dass jede Generation der litauischen Fürsten sowohl eine Ehe mit den Tverer Riurikiden als auch eine mit den masowischen Piasten schloss. ${ }^{29}$

26 Флоря, Борис Н.: Две грамоты князя Любарта (о луикой епископской кафедре в первой половине ХIV в.). Древнейшие государства Восточной Европы 1998. Москва 2000, S. 250-254; Idem: O грамоте Любарта Гедиминовича Луикой епископской кафедре. In: От Древней Руси к новой России. Юбилейный сборник, посвященный чл.-корр. РАН Я. Н. Щапову. Москва 2005, S. 177-181; Турилов, Анатолий А.: Жалованная грамота Любарта Гедеминовича Луцкой кафедре и ситуачия на Вольни после гибели галичко-волынских Рюриковичей. In: Восточная Европа в древности и средневековье. Проблемы источниковедения. XVII чтения памяти чл.-корр. АН CCCP В. Т. Пашуто. IV чтения памяти д. и. н. А. А. Зимина. Москва, 19-22 апреля 2005 г. Тезисы докладов. Ч. 2. Москва 2005, S. 266-268.

27 Келемьет, Станіслав: Любарт-Дмитро Гедимінович: периий илюб $і$ династичні права на ГалииљкоВолинсъке князівство. Ruthenica 15, Київ 2019, S. 141-167 (hier auch Quellen und Literatur).

28 Edition des Briefes: Russisch-livländische Urkunden. Gesammelt von K. E. Napiersky. St. Petersburg 1868, Nr. 49; БрэжгА, Баляслаў: Жалаба рыскае рады каниа ХІІІ стаг. Запісы Беларускага навуковага таварыства. Сш. 1. Вільня 1938, S. 35-40. Es ist bemerkenswert, dass zwei Forscher aus Litauen und Weißrussland, Darius Baronas und Wasil Waronin, diese Interpretation der Quelle gleichzeitig unabhängig voneinander vorschlugen - siehe Baronas, Darius - Dubonis, Artūras - Petrauskas, Rimvydas: Lietuvos istorija. T. 3. Valstybès iškilimas tarp Rytų ir Vakarų. Vilnius 2011, S. 458-460; Воронин, В. А.: Княжение Ольгерда в Витебске, S. 21-26.

29 Petrauskas, Rimvydas: Die Außenwelt der Gediminiden: Formen und Möglichkeiten internationaler Politik der heidnischen Großfürsten Litauens in der zweiten Hälfte des 14. Jahrhunderts. In: Akteure mittelalterlicher Au- 
Die Frage der Beziehungen Litauens zur Goldenen Horde bedarf einer speziellen Erörterung. Ein Problem ist auch hier die Knappheit der Quellen. Schon anhand dieser Zeugnisse kann man die Grundzüge dieser Beziehungen feststellen. Schon unter Mindowe (Mindaugas, $\uparrow 1263$ ) sollte Litauen auf das System der mongolischen Oberhoheit über die benachbarten russischen Länder stoßen: im Jahre 1259 unternahm der mongolische Heerführer Burundai einen Kriegszug gegen die wolhynischen Fürsten, der auch Litauen berührte. ${ }^{30}$ Nach dem Zerfall des Mongolischen Reichs hatte Litauen mit seiner Nachfolgerin, der Goldenen Horde, zu tun. Die litauischen Herrscher erkannten zunächst die Oberhoheit der Tataren an und versuchten, mit ihnen zusammenzuwirken: davon zeugt beispielweise die Erzählung der Ersten Novgoroder Chronik über die Reise des Novgoroder Bischofs nach Kiew 1331, wo ein tatarischer Baskak anwesend war, oder die Forderung des Khans Toktamisch im Jahre 1393 an Władysław Jagiełł, damals schon König von Polen (1386-1434), Tribut nach dem alten Brauch zu zahlen. ${ }^{31}$ Später, als die Wirren in der Goldenen Horde ausbrachen, versuchte Litauen, diese Lage auszunutzen und die tatarische Oberhoheit zu instrumentalisieren. So unternahm Witold Kriegszüge gegen Timur Kutluq, um nicht nur Toktamisch zu unterstützen, sondern auch seinen Machtbereich zu erweitern: eine zeitgleiche Quelle zeugt von den Burgen, die der Großfürst von Litauen im Süden erbauen ließ $;^{32}$ schon Antoni Prochaska zeigte, dass Witold von Toktamisch einen Jarliq für die litauische Rus' erlangte. ${ }^{33}$

In diesem Aufsatz konzentriere ich mich auf drei Fragen:

1. Hatten die litauischen Herrscher ein "gesamtrussisches Programm“?

2. Wie begründeten die litauischen Herrscher ihre Expansion in die Rus'?

3. Zu welchem Zeitpunkt konnte die Vereinigung der ganzen Rus' unter der Herrschaft Litauens stattfinden?

Benpolitik. Das Beispiel Ostmitteleuropas. Hg. v. Stephan Flemmig u. Norbert Kersken. Tagungen zur Ostmitteleuropa-Forschung 35. Marburg 2017, S. 53-67, hier S. 62-63.

30 GudAvičius, Edvardas: Mindaugas. Vilnius 1998, S. 256-262.

31 Новгородская первая летопись старшего и младшего изводов (= НПЛ). Подг. Арсений Н. Насонов. Москва - Ленинград 1950, S. 343-344; РАдлов, Василий В.: Ярлыки Тохтамыциа и Темир-Кутлуга. In: Записки Восточного отделения Императорского Русского археологического общества. 1888. T. III. Вып. I и II. Санкт-Петербург 1889, S. 1-40, hier S. 6; КАРский, Евфимий Ф.: Западнорусский ярлык хана Золотой орды Тохтамыша к польскому королю Ягайлу 1392-1393 г2. In: КАРский, Е. Ф.: Труды по белорусскому и другим славянским языкам. Москва 1962, S. 443-444.

32 Der Kaufmann Johann Ryman schrieb aus Polozk nach Riga am 25. Juli 1399: [...] de Ploschowers sid ut der reise comen, dar ze myt Vitoweten weren [...] Ok seghet men, wo Vitowe heft in Taterie II slod upslagen II dach vard van Kaffe to dem mere werd an enen water het Bochowe Rekkee [...]. Siehe in Riga, Latvijas valsts vēstures arhīvs, 673. f. (Rīgas mağistrāta ārējais arhīvs), 4. apr., 18. k., 801 . Die Edition dieses Briefes befindet sich in Vorbereitung.

33 Prochaska, Antoni: Z Witoldowych dziejów. Przegląd Historyczny 15/3, 1912, S. 259-270. Die Hypothese des ukrainischen Forschers Feliks Šabuldo, dass dieser Jarliq schon zu Zeiten Olgerds ausgestellt wurde, ist umstritten. 


\section{Das „gesamtrussische Programm” Litauens?}

In der Forschungsliteratur wird häufig angenommen, dass die litauischen Fürsten ein Programm des außenpolitischen Handelns hatten; manche Forscher behaupten, dass dieses Programm unter anderem die Unterwerfung der ganzen Rus' vorsah.

Setzten sich die litauischen Fürsten wirklich zum Ziel, die ganze Rus' unter ihrer Macht zu vereinigen? Wenn wir uns diese Frage stellen, fällt es vor allem auf, dass direkte Quellenaussagen zu diesem Thema fast fehlen. Es wäre berechtigt, die Formulierung eines solches Programms in den Quellen aus jedem Zeitalter zu suchen, in dem die litauische Politik ein großes Ausmaß erreichte, also in solchen aus dem 14. Jahrhundert. Das fällt schon deswegen schwer, weil sehr wenige „Ich-Aussagen“ der litauischen Fürsten und ihrer Untertanen aus der behandelten Epoche überliefert sind. Es wäre problematisch, die Formulierung eines solches Programms zu erwarten, weil Litauen im eigenen Sinne (Lithuania propria), der politische Kern des Staates, ein heidnisches Land blieb, in dem die pragmatische Schriftlichkeit und publizistische Literatur erst sehr kurz entwickelt waren. Bis zum Ende des 14. Jahrhunderts hatten die litauischen (Groß) Fürsten keine institutionalisierte Kanzlei und befriedigten ihre Bedürfnisse nach den schriftlichen Verträgen aus der Kraft der Gegenseite. ${ }^{34}$ Sogar in den Fällen, in denen relativ wenige Gelehrte im Dienst der litauischen Fürsten bekannt sind, gehörten diese Leute - katholische Mönche ${ }^{35}$ und orthodoxe Schreiber ${ }^{36}$ - zu anderen Kulturkreisen als ihre heidnischen Auftraggeber, was eine gewisse Distanz schuf. ${ }^{37}$ Die litauische literarische Tradition beschränkte sich im Gegensatz zur nord-östlichen und nord-westlichen Rus' auf wenige Werke, die ab Ende des 14. Jahrhunderts bis Mitte des 15. Jahrhunderts

34 Kosman, Marceli: Kancelaria wielkiego księcia Witolda. Studia Źródłoznawcze 14, 1969, S. 91-119, hier S. 95-99; Rowell, Stephen C.: A pagan's word. Lithuanian diplomatic procedure 1200-1385. Journal of Medieval History 18, 1992, S. 145-160.

35 Gemeint sind die berühmten Briefe Gedimins. Siehe die neueste Edition: Chartularium Lithuaniae res gestas magni ducis Gedeminne illustrans. Gedimino laiškai. Ed. Stephen C. Rowell. Vilnius 2003 (zu den Schreibern besonders Nr. 54).

36 Es handelt sich um den Brief Olgerds an den Patriarchen von Konstantinopel 1370 oder 1371; ediert in: Acta Patriarchatus Constantinopolitani MCCCXV - MCCCCII. Ed. Franz Miklosich et Ioseph Müller. T. 1. Vindobonae 1860, Nr. 320, S. 580-581; Русская историческая библиотека (= РИБ) 6. Памятники древнерусского канонического права. Ч. 1 (Памятники XI-XV в.). Санкт-Петербург 1908², 2. arabische Paginierung, Sp. 135-140 (griechischer Text mit russischer Übersetzung); deutsche Übersetzung: KrÜGer, H.: Ein Brief des Litauerfürsten Olgerd an den Patriarchen von Konstantinopel. Mitteilungen der Litauischen literarischen Gesellschaft 29 (V. 5). Heidelberg 1907, S. 358-361; zur Datierung: Беспалов, Роман А.: О писъме Ольгерда патриарху Филофею. Древняя Русь. Вопросы медиевистики (= ДРВМ) 2 (60), 2015 , S. 49-62). Es wird angenommen, dass er ursprünglich auf Russisch geschrieben und erst in der Empfängerkanzlei ins Griechische übersetzt wurde (RočKA, Marcelinas: Algirdo laiškas Konstantinopolio patriarchui. Senoji Lietuvos literatūra 4: Metraščiai ir kunigaikščių laiškai. Vilnius 1996, S. 193-204, hier S. 200-202; vgl. РИБ 6, Sp. 139-140, Anm. 4). Nach der Auskunft von Dr. Andrey Vinogradov in seiner E-Mail vom 3. August 2020, ist der überlieferte Text von einer Person geschrieben, die griechische Umgangssprache

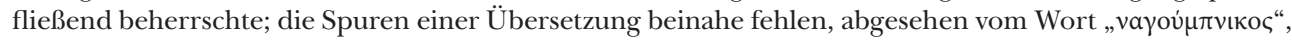
das für einen Amt oder eine Würde steht.

37 Łowmiański, H.: Uwagi, S. 413; Baronas, Darius: Trys Vilniaus kankiniai. Gyvenimas ir istorija. (Istorine studija ir šaltiniai). Fontes ecclesiastici historiae Lithuaniae 2. Vilnius 2000, S. 108-115. 
entstanden sind und dynastische oder bloß lokale Angelegenheiten behandelten. ${ }^{38}$ Es darf sogar gefragt werden: War eine Formulierung und konsequente Durchsetzung eines „Programms“ möglich, als der Großfürst selbst das einzige ständige Machtinstitut war?39 Die Frage scheint rhetorisch zu sein. Deswegen können wir die litauische Expansion vorwiegend mit den Augen der äußeren Beobachter betrachten. Sowohl ihre Zeugnisse als auch die wenigen „Ich-Aussagen“ sollten in ihrem jeweiligen Kontext analysiert werden.

Es wird häufig behauptet, dass die litauischen Herrscher ein Programm zur Unterwerfung der ganzen Rus' hatten. Es werden zwei Äußerungen der litauischen Fürsten darüber herangezogen. Die erste ist die berühmte Aussage auf den Verhandlungen mit den Gesandten Kaiser Karls IV. - dem Erzbischof Ernst von Prag, Deutschmeister Wolfram von Nellenburg und Fürst Nikolaus II. von Troppau - wegen der Taufe Litauens im Jahre 1358: omnis Russia ad Letwinos deberet simpliciter pertinere. ${ }^{40} \mathrm{Im}$ Kontext betrachtet sieht die Bedeutung dieser Phrase jedoch ganz anders aus: Item postulabant, quod ordo locaretur ad solitudines inter Tartaros et Rutenos ad defendendum eos ab impugnacione Tartarorum et quod nihil iuris ordo sibi reservaret apud Rutenos, sed omnis Russia ad Letwinos deberet simpliciter pertinere. Es handelte sich darum, dass der Deutsche Orden nach Süden übersiedelt werden sollte, um gegen die Tataren Krieg zu führen, dabei sollte er keinen Anspruch auf die benachbarte Rus' haben. ${ }^{41}$ Der Zweck der litauischen Seite war, die in Preußen und Livland entstandene Situation zu vermeiden, wo die Bekehrung der Heiden zu ihrer Unterwerfung unter die Macht des Deutschen Ordens und seiner Behauptung als Landesherrn führte. Diese Forderung ist nicht mit dem angeblichen „gesamtrussischen Programm“ in Verbindung zu bringen, ${ }^{42}$ sondern vielmehr mit den Wirren innerhalb der Goldenen Horde nach dem Tod des Khans Dschanibek (1357). ${ }^{43}$ Sogar in solcher

38 ЧАмярыцкі, Вячаслаў А.: Беларускія летапісы як помнікі літаратуры. Мінск 1969. Das neueste Studium über die Anfänge der litauischen Geschichtsschreibung (Лицкевич, Олег В.: «Летописеи великих князей литовских и «Повесть о Подолье: опыт комплексного критического разбора. Санкт-Петербург 2019) war mir noch nicht zugänglich.

39 Petrauskas, Rimvydas: Die Staatsstrukturen des frühen Grossfürstentums Litauen. In: Litauisches Kulturinstitut, Jahrestagung 2003. Lampertsheim 2004, S. 13-26.

40 Scriptores rerum Prussicarum (= SRP). T. 2. Die Geschichtsquellen der preussischen Vorzeit bis zum Untergange der Ordensherrschaft. Hg. v. Th. Hirsch, M. Töppen u. E. Strehlke. Leipzig 1863, S. 80.

41 Über diese Verhandlungen siehe NikžEnTAITIS, Alvydas: Lietuvos diplomatijos veikla Vidurio Europoje XIV a. VI dešimtmetyje. Lituanistica 3, 1991, S. 3-12; Idem: Die friedliche Periode in den Beziehungen zwischen dem Deutschen Orden und dem Großfürstentum Litauen (1345-1360) und das Problem der Christianisierung Litauens. Jahrbücher für Geschichte Osteuropas NF 41 (59), 1993, S. 1-22; BAronas, Darius - Rowell, Stephen Christopher: The Conversion of Lithuania: From Pagan Barbarians to Late Medieval Christians. Vilnius 2015, S. 141-143 (mit Quellen- und Literaturhinweisen).

42 Diese Bedeutung der Forderung der litauischen Fürsten erkannte auch Henryk Łowmiański an. Sein darauffolgender Versuch, die Entlehnung des „großrussischen Programms der Vereinigung aller russischen Länder" durch die Ehe Olgerds mit Julianna, der Tochter des Großfürsten Alexander von Tveŕ, zu beweisen, ist nicht überzeugend (Ловмяньский, Х.: Русско-литовские отношения, S. 272-273). Zur (knappen) Rolle Juliannas im politischen Leben Litauens zur Regierungszeit Olgerds, die in der Literatur manchmal übertrieben wird, siehe Baronas, Darius: Julijona - Lietuvos didžiojo kunigaikščio Algirdo žmona ir jo vaiku motina. Lietuvos istorijos metraštis 2, 2019, S. 5-39.

43 Vielleicht äußerte Olgerd seine Ansprüche auf den Verhandlungen mit den kaiserlichen Gesandten, weil der neue Khan Berdi Beg kurz nach seiner Thronbesteigung einen Jarliq für den Metropoliten 
Formulierung war dieses Forderung irreal; ebenso irreal waren die Forderungen der Litauer bezüglich des Deutschen Ordens. ${ }^{44}$

Die zweite Stelle stammt aus der Erzählung über die Verhandlungen Witolds mit Toktamisch vor der berühmten Schlacht bei Worskla (1399), also Ende 14. Jahrhundert. Laut einigen russischen Chroniken bat Witold den tatarischen Khan Toktamisch darum, ihn auf den Moskauer Großfürstenthron zu setzen, wenn sie seinen Rivalen Timur-Qutlug besiegen; ${ }^{45}$ die Bestätigung dieser Erzählung sieht man manchmal in den Jarliqen der tatarischen Khane für die Großfürsten von Litauen, in denen ihnen verschiedene russische Länder verliehen werden. ${ }^{46}$ Dazu kann man bemerken, dass die ganze Erzählung in den Witold-feindlichen Chroniken wohl Anfang 15. Jahrhundert auftaucht. Wie Jaroslaw Pelenski mit Recht bemerkte, spiegelt diese Erzählung die in Moskau und Novgorod herrschende Besorgnis über die Pläne Witolds wider. ${ }^{47}$ In der ersten Novgoroder Chronik überwiegen die moralisierenden Sentenzen anlässlich der Niederlage Witolds, der Verfasser fühlt mit seinen Untertanen mit, die als ein Teil der christlichen Welt dargestellt werden; erst in der IV. Novgoroder Chronik gewinnt die Rhetorik an „geopolitischen“ und Litauen-feindlichen Motiven. ${ }^{48}$ Darüber hinaus wäre, wie selbst die Ereignisse am Ende 14. Jahrhundert zeigen, die militärische Unterwerfung der Rus' eine sehr komplizierte Aufgabe gewesen. In den zeitgenössischen Quellen werden die Versuche Witolds, Groß-Novgorod und Pleskau seiner Macht zu unterstellen, ziemlich ausführlich beschrieben. Der litauische Großfürst sagte ihnen sogar ab und unternahm später Kriegszüge gegen sie, aber diese Bemühungen blieben ergebnislos. ${ }^{49}$

Aufschlußreich ist die Titulatur der litauischen Herrscher. Es fällt auf, dass sie nie die Titulatur der „Großfürsten der ganzen Rus'“ gebrauchten ${ }^{50}$ - besonders wenn man diese Situation mit der Stellung der nord-östlichen Riurikiden vergleicht, die ziemlich früh anfingen, sich „Großfürsten der ganzen Rus'“ zu nennen: obwohl der Titel, allerdings

Alexios ausstellte, der Dmitrij von Moskau unterstützte und mit den Metropoliten Olgerds konkurrierte (ГРигорьев, Аркадий П.: Сборник ханских ярлыков русским митрополитам. Источниковедческий анализ золотоордынских документов. Санкт-Петербург 2004, S. 72-115).

44 Petrauskas, R.: Die Außenwelt, S. 61.

45 Ihre Liste und Analyse bei Pelenski, Jaroslaw: Russia and Kazan. Conquest and Imperial Ideology (1438-1560s). The Hague - Paris 1974, S. 156-170.

46 Die neueste Edition: KoєodzIEjczyк, Dariusz: The Crimean Khanate and Poland-Lithuania. International Diplomacy on the European Periphery $\left(15^{\text {th }}-18^{\text {th }}\right.$ Century). A Study of Peace Treaties Followed by Annotated Documents. The Ottoman Empire and Its Heritage. Politics, Society and Economy 47. Leiden - Boston 2011, besonders S. 529-533, 539-544.

47 Pelenski, J.: Russia and Kazan, S. 166.

48 Севастьянова, Ольга Валентиновна: Новгородская Четвертая летопись как источник по изучению политических взглядов новгородского архиепископа Евфимия II. ДРВМ 2 (40), 2010, S. 56-73, hier S. 71-73.

49 ПСРЛ 4. Вып. 1, S. 378-379; НПЛ, S. 393-394; Псковские летописи. Выпуск 2. Подг. Арсений Н. Насонов. Москва - Ленинград 1955, S. 30; Московский летописный свод кониа XV в. ПСРЛ 25. Москва - Ленинград 1949, S. 227-228. Über die Versuche Witolds, die Länder der nord-östlichen und nordwestlichen Rus' im nächsten Jahrhundert zu erobern, siehe unten.

50 Adamus, Jan: O tytule panujacego i państwa Litewskiego pare spostrzeżeń. Kwartalnik Historyczny 44/1, 1930, S. 313-332; SKuRvydarté, Loreta: Lietuvos valdovo Vytauto titulatūra: kada Vytautas ima tituluotis didžiuoju kunigaikščiu? Lietuvos istorijos studijos 8, 2000, S. 9-19. 
als Ehrenbezeichnung, schon vor dem mongolischen Einfall in Gebrauch war, stammen die ersten Belege dieser Titulatur aus der ersten Hälfte des 14. Jahrhunderts. ${ }^{51}$ Gedimin war lediglich Gedeminne Letwinorum et multorum Ruthenorum rex, ${ }^{52}$ wie auch Witold in seinen lateinischen Urkunden Alexander alias Wythowdus Dei gracia magnus dux Lithvanie et terrarum Russie dominus atque heres war, ${ }^{53}$ in den russischen bzw. ruthenischen Schreiben fungierte auch Witolds Titel von Gottes Gnaden Großfürst von Litauen und vielen russischen Ländern. ${ }^{54}$ Ein für den litauischen Staat ungewöhnlicher Herrschertitel wird im Brief Olgerds an den Patriarchen von Konstantinopel verwendet. In der Intitulatio nennt sich der Sohn Gedimins „Basileus“. Da die Forscher anhand von Stilmerkmalen annehmen, dass der Brief in seiner überlieferten Form eine Übersetzung aus dem Russischen darstellt, stand im russischen Original wohl der Titel „Zar“. Das Studium von Vladimir Vodoff über den Gebrauch des Zarentitels in russischen Quellen zeigt, dass dahinter wahrscheinlich keine Ansprüche auf die weltliche Herrschaft stehen, sondern auf die Kaisermacht über die Kirche. ${ }^{55}$ Hier fällt was anderes auf: in demselben Brief bittet Olgerd den Patriarchen nicht um einen Metropoliten für die ganze Rus', sondern für einen Sondermetropoliten für Kiew, Smolensk, Tveŕ, Kleinruthenien, Nowosil und Nischni Novgorod - also für Olgerds Untertanen und Verbündete.

\section{Warum soll die Rus' den Litauern gehören?}

In den schon genannten Quellen aus den ersten Jahrzehnten des 15. Jahrhunderts wird die Frage der litauischen Oberhoheit über die russischen Länder sehr knapp behandelt. Es scheint, dass Witold und Intellektuelle in seinem Dienst die Macht des litauischen Herrschers über die russischen Länder als etwas Natürliches wahrnahmen. Die Quelle

51 Vgl. dazu die jüngste Diskussion (mit Quellen- und Literaturhinweisen): Кучкин, Владимир А.: О принятии Михаилом Ярославичем Тверским и владимирскими князъями титула «великий князь всея Pycu». In: Михаил Ярославич Тверской - великий князь всея Руси. Тверь 2008, S. 8-21; Горский, Антон А.: Титулование «всея Руси» и русские князья XI-XIII вв. In: Ibid., S. 43-50.

52 Chartularium Lithuaniae, S. 38 (Zitat), vgl. S. 46, 58, 62, 218.

53 Vitoldiana. Codex privilegiorum Vitoldi magni ducis Lithuaniae, 1386-1430. Wyd. J. Ochmański. Polska Akademia Nauk. Oddział w Poznaniu. Ser. Historia. T. 8. Warszawa - Poznań 1986, Nr. 26-29, 33-35, 90, 94, 100, 101, 185 (Zitat aus Nr. 26).

54 Siehe beispielsweise den Vertrag des Großfürsten Boris Aleksandrovič von Tveŕ mit Witold 1427: $c$ [...] великимг кн(я)з(е)мг Витовтомг Литовъским и многихъ Русъскихъ земль господаремъ (ДДГ, Nr. 23, verglichen mit dem Original: Российский государственный архив древних актов, ф. 27 (Приказ Тайных Дел), оп. 1, Nr. 2). Eine Erwähnung der „vielen russischen Länder“ enthielt auch der Titel Swidrigals, der nach dem Tode Witolds den großfürstlichen Thron bestieg, in seinem Vertrag mit Groß-Novgorod 1431, der in stark beschädigter Form überliefert ist (ГВНП, Nr. 63, S. 105). In den russischen Urkunden zu inneren Angelegenheiten nannte sich Witold in der Regel lediglich „Großfürst“, ohne Territorialbezeichnungen.

55 Водов, Владимир: Замечания о значении титула 'иаръ' применительно к русским князъям в эпоху до середины XV века. In: Из истории русской культуры. Т. II. Кн. 1: Киевская и Московская Русь. Москва 2002, S. 506-542. (Französisches Original: Vodoff, Vladimir: Remarques sur la valeur du terme "tsar" appliqué aux princes russes avant le milieu du XVe siècle. Oxford Slavonic Papers NS 11, 1978, S. 2-41). Zur Sprache des Briefes vgl. oben Anm. 36. 
dieser Macht war laut diesen Quellen „Gottes Gnade. “56 So steht es in der Arenga der Verleihungsurkunde Jagiełłos für seinen Bruder Skirgiello 1387: „Gott gab uns viel.“57 Ähnlich klingen die Aussagen Witolds in seinem Brief an den Großfürsten Ivan von Tveŕ über die Weihe des Metropoliten Grigorij Zamblak (1415): „von Gottes Gnaden haben wir die Stadt Kiew inne“, „nach der Beratung mit unseren Gebrüdern und mit den russischen Fürsten unserer russischen Länder, was uns von Gott unterworfen wurde. "58 Aber obgleich auch nach Gottes Wille, sollte diese Unterwerfung mit irdischen Mitteln durchgesetzt werden. Die militärische Eroberung wurde von den litauischen Herrschern, ihren Räten und Intellektuellen als ganz berechtigt betrachtet. ${ }^{59}$ Davon zeugen nicht nur Handlungen und Aussagen in fürstlichen Briefen an fremde Herrscher, sondern auch eine historische Darstellung, die den Untertanen der Gediminiden zugänglich war - die „Erzählung über Podolien“, die kurz nach dem Tode Witolds entstand und die Rechte Litauens auf das von Polen eroberte und somit zu einem Erisapfel gewordene Westpodolien begründen sollte. ${ }^{60}$

In diesem Werk fand noch eine in der Gesellschaft des Großfürstentums Litauen eingebürgerte Konzeption ihren Niederschlag - die „alte Zeit“ oder „alte Sitten“ (starina), die als Vorbild für die Gegenwart und Zukunft dienen sollten. ${ }^{61}$ Podolien solle dem Großfürstentum Litauen nach dem Tod Witolds deswegen gehören, weil es vor langem schon durch die Gediminiden erobert sei. Das Motiv der Eroberung ist viel schärfer in den Schreiben der litauischen Herrscher ausgeprägt, die ihren Kontakten mit den westlichen Mächten, vor allem mit dem Heiligen Stuhl gewidmet sind, auch wenn diese Schreiben nicht überliefert sind und ihr Inhalt nur aus der Antwort der Gegenseite bekannt ist. So erteilte Papst Alexander IV. am 6. März 1255 König Mindowe eine Bulle,

56 Diese Formel taucht sogar im Titel des heidnischen Herrscher Gedimins auf (Chartularium Lithuaniae, S. 46).

57 Полочкие грамоты XIII - начала XVI века. Отв. ред. Анна Л. Хорошкевич. Подг. Сергей В. Полехов, Василий А. Воронин, Александр И. Груша, Александр А. Жлутко, Екатерина Р. Сквайрс, Андрей Г. Тюльпин. Т. 1. Москва 2015, Nr. 16.

58 [...] божиим изволением тое место Киев мы обладаем [...] згадавше с нашею братъею, и со князми рускими наших руских земель ито нам есть Богом покорено (zitiert nach: Афанасенко, Юрий: Новогрудский собор 1415 г. в иерковной политике великого князя Витовта. Studia historica Europae Orientalis 8, 2015, S. 91122, hier S. 120; vgl. die ältere Edition nach der anderen Vorlage: Акть, относящиеся к истории Западной России (= АЗР) 1: 1340-1506. Санкт-Петербург 1846, Nr. 25, hier S. 36).

59 Allerdings herrschten solche Vorstellungen auch unter den abendländischen Gelehrten jener Epoche (Sutherland, Donald: Conquest and Law. Studia Gratiana 15. Romae, 1972. S. 33-51).

60 ПСРЛ 35, Москва 1980, S. 66-67. Dazu ausführlich Полехов, Сергей В.: Летописная «Повесть о Подолъе». [Ч. 1]. ДРВМ 1 (55), 2014, S. 33-42; Idem: Летописная «Повесть о Подолье.. (Окончание). ДРВМ 2 (56), 2014, S. 49-62.

61 Auf die vergangene Zeit beruft sich auch Olgerd in seinem Brief an den Patriarchen von Konstantinopel, indem er den Metropoliten Alexios der Begünstigung Moskaus beschuldigt. Über die Konzeption der starina siehe Кром, М. М.: Меж Русью и Литвой. Прил. IV: «Старина» как категория средневекового менталитета, S. 288-309 (hier auf S. 290-291 auch andere Beispiele aus der Zeit Witolds); IDEм: Понятие «старинъ» в политической и правовой культуре Великого княжества Литовского XV-XVI веков. In: Наш радавод. Кн. 3. Ч. 3. Гродно 1991, S. 540-544; ГрушА, Александр И.: Кризис доверия? Появление и утверждение правового документа в Великом Княжестве Литовском (конеи XIV - первая треть XVI в.). Москва - Санкт-Петербург 2019, S. 60-89. 
mit der er die Eroberungen des litauischen Herrschers in den benachbarten russischen Ländern auf seine Bitte bestätigt mit der Hoffnung, Mindowe werde sie zum wahren Christenglauben führen. ${ }^{62}$ Ein anderes Beispiel ist die Supplik Jagiełłos und Witolds an Papst Gregor XII. mit der Bitte um einen Ablass für die Teilnehmer des Kriegszuges Witolds gegen die „Ungläubigen“ - „die Russin und heydin“, wie in der Chronik des pomesanischen Offizials steht; gemeint ist wohl Pleskau, gegen das Witold und der Deutsche Orden in Livland damals einen Krieg führten. ${ }^{63}$ Es sei noch ein Umstand betont: fast in allen diesen Fällen betrachten die Litauer die benachbarten russischen Länder lediglich als ein Handlungsobjekt.

Wenn man die Wichtigkeit des dynastischen Faktors im politischen Denken des damaligen Großfürstentums Litauen in Betracht zieht, dann ist es gar nicht erstaunlich, dass sich diese Vorstellungen in der Konzeption der „Vatererbe“ äußerten. Die russischen Länder wurden als die „Vatererbe“ der litauischen Fürsten wahrgenommen und dargestellt. Ein gutes Beispiel ist der Vertrag des Großfürsten von Tveŕ Boris Aleksandrovič mit Witold 1427, in dem nicht nur Witebsk und Kiew, sondern auch Smolensk, Wiazma und Dorogobuž zum „Vatererbe“ Witolds zählen ${ }^{64}$ - obwohl Witebsk im 14. Jahrhundert zu den Besitzungen Olgerds und später Jogailas gehörte, und in Kiew bis 1394 Wladimir Olgerdovič herrschte; die letzten drei Städte wurden dagegen erst von Witold erobert und dem litauischen Staat angegliedert. Laut Witolds Briefen entscheiden gerade die Fürsten - sowohl Witold als auch seine Nachbarn - über die Schicksale ihrer Untertanen; eine Ausnahme sind wohl die Novgoroder und Pleskauer wegen ihrer speziellen Staatsform. Das Motiv der Sorge des Herrschers um seine Untertanen ist jedoch auch in Witolds Äußerungen zu finden. Als er die Weihe eines litauischen Metropoliten erwägt, berät er sich mit seinen Untertanen und sorgt sich um ihr Seelenheil, obwohl er eines anderen Glaubens ist. ${ }^{65}$ In der ersten Fassung der Lobrede für Witold (1428) wird er für die Sorge um den Wohlstand seines Landes gelobt. ${ }^{66}$ Dieses Motiv ist auch in der „Erzählung über Podolien“ sichtbar: die Fürsten Koriatoviči befreien Podolien vom tatarischen Tribut und lassen Burgen bauen, später kommt Witold den Bitten Jagiełłos entgegen, das Land nach dem Tode Spytkos von Mielsztyn zu übernehmen, um es vor den Tataren zu verteidigen.

62 Vetera Monumenta Poloniae et Lithuaniae gentiumque finitimarum historiam illustrantia. 1. Ed. Augustinus Theiner. Romae 1860, Nr. 123, S. 61. Vgl. die Erwähnungen über die Länder, die Mindowe den Ungläubigen schon entriss oder noch entreißen wird, in den päpstlichen Schreiben, beispielweise in der Bulle Innozenz' IV. vom 17. Juli 1251 (Analecta Vaticana 1202-1366. Ed. Jan Ptaśnik. Monumenta Poloniae Vaticana. T. 3. Cracoviae 1914, Nr. 67).

63 SRP 3, S. 288 (Zitat); Berlin, Geheimes Staatsarchiv Preußischer Kulturbesitz, XX. Hauptabteilung (Königsberger Archiv), Ordensbriefarchiv, Nr. 861, Bl. 2, ediert künftig als Anhang bei Polechov, S.: Zwischen Kreuzzügen (im Druck).

64 А пошлину имати с моих со тфьрьских люде[и] в моего господина, дьда, великого князя Витовта, отиине в Смоленьску, в Витебску, н[а Киевъ], в Дорогобужи, в Вязмь и по всему его великому княженью по давному (ДДГ, Nr. 23, siehe auch oben Anm. 55).

65 АЗР 1, Nr. 25; Афанасенко, Ю.: Новогрудский собор, S. 119-122.

66 Западно-руские (литовские) летописи. ПСРЛ 17. Санкт-Петербург 1907, Sp. 417-420: Тако же и отечьство его, Литовъская земля, в величеи ч(ес)ти предстояше, и всяким обильемг исполнятеся, тако же и народна бяше много. 
Im Großen und Ganzen gibt es in Litauen viel weniger aussagekräftige Quellen, die die Machtideologie spüren lassen, als in Moskau oder Tveŕ. Wenn wir die Lobrede für Witold mit analogen Werken über Dmitrij Donskoj oder Michail Aleksandrovič von Tveŕ vergleichen, fällt es auf, dass der Verfasser (oder: die Verfasser) sich hauptsächlich mit der Stellung Witolds auf der internationalen Bühne befasst. In der ersten Fassung der Lobrede für Witold steht: „Er hatte viele Jahre das Großfürstentum von Litauen und Rus' inne sowie andere Großfürstentümer, einfach gesagt, das ganze Land Rus'“. Könnte man hier einen Hinweis auf das politische Programm Witolds sehen? Ferner wird aber die Existenz anderer Großfürstentümer und Länder anerkannt. Es ist auch was anderes bemerkenswert: diese Formulierung befindet sich in der ersten, 1428 entstandenen Fassung der Lobrede für Witold, als seine Position in der Rus' nach dem Tode seines Schwiegersohnes Vasilij I. von Moskau während der Minderjährigkeit seines Enkels Vasilij II. besonders stark war. Jedoch führte auch das nicht zur Anerkennung der Oberhoheit Witolds durch Groß-Novgorod und Pleskau.

\section{Verpasste Gelegenheiten der Vereinigung?}

Wenn wir das Problem von der praktischen Seite her betrachten, scheint die Existenz eines zielgerichteten Programms der Unterwerfung der ganzen Rus' höchst unwahrscheinlich zu sein. Eine eventuelle Eroberung der Rus' war sowohl mit logistischen als auch mit geopolitischen Problemen verbunden.

Von diesen Problemen zeugt die ganze Regierung Olgerds sehr gut. Nachdem er Groß-Novgorod kurz nach seinem Regierungsantritt angriff, beklagte sich der Moskauer Fürst, damals auch der Großfürst von Vladimir, Simeon der Stolze bei Khan Usbek darüber, dass der litauische Herrscher seine „Vatererbe plünderte“. Darauf nahm der Khan die Gesandten des litauischen Großfürsten gefangen, die nach einer heftigen Niederlage vom Deutschen Orden gerade bei ihm Hilfe suchten. ${ }^{67}$ Danach kam es während der ganzen Regierungszeit Olgerds, also fast dreißig Jahre lang, zu keinen Versuchen, Groß-Novgorod politisch zu unterwerfen; es gab nur kleinere Auseinandersetzungen um Pleskau oder mit dieser Republik, die gerade ihre Selbständigkeit behauptete, und die Versuche, die Stadt am Wolchow dem litauischen Metropoliten unterzustellen. Die Auseinandersetzung mit Moskau spielte sich hauptsächlich auf dem kirchenpolitischen Feld sowie in den historischen Smolensker und Tschernigower Ländern ab. ${ }^{68}$ Dazu führten Olgerd, seine Brüder und weitere Verwandten Kriege im Süden um das Wolhynische Erbe gegen Polen und Ungarn sowie im Norden gegen den Deutschen Orden. Seine berühmten Kriegszüge gegen Moskau 1368, 1370 und 1372 hatten wohl zum Ziel, den

67 ПСРЛ 15. Вып. 1, Sp. 57-59.

68 Флоря, Борис Н.: Борьба московских князей за смоленские и черниговские земли во второй половине ХIV в. Проблемы исторической географии России. Вып. 1. Формирование государственной территории России. Москва 1982, S. 58-80; Кучкин, Владимир А.: К изучению прочесса иентрализачии в Восточной Eвропе (Ржева и её волости в XIV-XV вв.). История СССР 6, 1984, S. 149-161; MeyendorfF, John: Byzantium and the rise of Russia. Cambridge etc. 1981. 
(Groß)Fürsten Dmitrij von Moskau dazu zu zwingen, seine Ansprüche auf das Großfürstentum Vladimir aufzugeben und Sicherheit sowie die Großfürstenwürde von Fürst Michail von Tveŕ anzuerkennen. Diesen Zweck verfolgte Olgerd, indem er die Gefangenen auf dem Wege nach Moskau 1368 laut der Chronik-Erzählung fragte: „Wo ist der Großfürst, gibt es Macht bei ihm?"69 Es ist charakteristisch, dass Dmitrij 1368 und 1370, als Olgerd Moskau erreichte, die Stadt nicht verließ, anders als während des Angriffs von Toktamisch 1382. ${ }^{70}$ Allem Anschein nach hielt Dmitrij seinen Tod im Krieg mit Olgerd für unwahrscheinlich. ${ }^{71}$ Es ist bemerkenswert, dass Olgerd keinen eigenen Kandidaten für den fürstlichen Thron von Moskau hatte. Es handelte sich dabei nicht um Moskau, sondern vielmehr um das Großfürstentum Vladimir. Die Khane der zerfallenden Goldenen Horde waren an diesem Konflikt auch beteiligt, was sowohl von Dmitrij als auch von Michail anerkannt war, und hatten keinen Grund, den Jarliq auf den großfürstlichen Thron jemandem außerhalb der nord-östlichen Rus' zu verleihen.

Noch besser zeugen von diesen Schwierigkeiten die Ereignisse vom Anfang des 15. Jahrhunderts, als Großfürst Witold einen Krieg mit Vasilij I. führte und zwei mächtige Züge gegen Moskau 1406 und 1408 unternahm. Manchmal wurde dem litauischen Großfürsten vorgeworfen, dass er in diesem Konflikt zögerte, den entscheidenden Schlag zu versetzen, der den Aufstieg Moskaus verhindern könnte. ${ }^{72}$ In Wirklichkeit sah alles anders aus. Ein aufschlußreiches Beispiel ist der Brief des Komturs von Ragnit Graf Friedrich von Zollern an den Hochmeister des Deutschen Ordens Konrad von Jungingen vom 2. September 1406 aus Brjansk über den Kriegszug Witolds gegen Vasilij I., an dem auch die Truppen des Deutschen Ordens teilnahmen. Der Komtur berichtete über einen schwierigen Weg durch die heide mit seltenen Dörfern, wo es kompliziert ist, Kost, Getränke und Futter zu kriegen, und unklar bleibt, wie lange die Reise noch dauert; selbst der Ausstellungsort ist aussagekräftig: Gegeben tzu Brentzs LVI milen gelegen verrer voen di Tunepper (Dnjepr). ${ }^{73}$ Als Witold und seine Verbündeten den Kriegszug nach zwei Jahren wiederholten, litten sie beim Rückzug wiederum an Hunger und sollten wegen der Pferdekrankheit ihre Waffen unterwegs teilweise verlassen. ${ }^{74}$ Während der Kriegs-

69 ПСРЛ 15. Вып. 1, Sp. 89: Кде есть князь великїи, есть ли около его сила?

70 Долманьош, Иштван: Политика личной безопасности и военной зашить великих русских князей в Средневековъе. Русские аналогии некоторым европейским «регифугиям». In: Etudes historiques hongroises 1985 publiées à l'occasion du XVI ${ }^{\mathrm{e}}$ Congrès International des Sciences Historiques par le Comité National des Historiens Hongrois 1, Budapest 1985, S. 151-177; Горский, А. А.: Москва и Орда, S. 103-106.

71 Wladimir Kučkin datiert Dmitrijs erstes Testament auf Januar 1372 und verbindet seine Zusammenstellung mit dem Geburt des großfürstlichen Sohns Vasilijs (des späteren Großfürsten von Moskau) und der Heirat Wladimirs von Serpuchov mit der Tochter Olgerds (Кучкин, Владимир А.: Первая духовная грамота Дмитрия Ивановича Донского. Средневековая Русь. Вып. 2. Москва 1999, S. 46-78, besonders S. 57-67; das stark beschädigte Original ist ediert in: ДДГ, Nr. 8; Кучкин, Владимир А.: Издание завешаний московских князей XIV в. Первая душевная грамота великого князя Дмитрия Ивановича. ДРВМ 2009, Nr. 2 (36), S. 110-113.

72 Kritisch dazu: Jóźwiak, Sławomir - Kwiatkowski, Krzysztof - SzwedA, Adam - Szybkowski, Sobiesław: Wojna Polski i Litwy z Zakonem Krzyżackim w latach 1409-1411. Malbork 2010, S. 41.

73 CEV, Nr. 347.

74 Darüber berichten sowohl der Annalista Thorunensis als auch Jan Długosz (SRP 3, S. 291; DŁugosz, Jan: Annales seu Cronicae incliti Regni Poloniae. Lib. X et XI (1406-1412). Varsaviae 1997, S. 20-21). 
züge gegen Pleskau 1426 und Groß-Novgorod 1428 stieß Witold trotz der langen Vorbereitungen auf logistische Schwierigkeiten. ${ }^{75}$ Wenn wir uns auch an die ziemlich losen Verhältnisse der östlichen Randgebiete und Vasallenfürstentümer zum Großfürsten von Litauen erinnern ${ }^{76}$ zeigen die angeführten Beispiele, dass eine militärische Unterwerfung der entfernten Länder mit dem entwickelten „staatlichen“ Selbstbewußtsein sogar unter den damaligen Bedingungen (die Union mit Polen) irreal war.

Ein anderer Zeitpunkt, den die Vertreter der „litauischen Alternative für die ganze Rus'“ nennen, wäre die Zeit der Verhandlungen zwischen Jogaila und seiner Familie einerseits und dem Moskauer Riurikidenzweig andererseits über die dynastische Ehe. Informationen darüber sind lediglich in einem Regest der entsprechenden Verträge im Inventar des Archiv von Posolskij Prikaz, also dem Moskauer Auswärtigen Amt, aus dem Jahre 1627 überliefert. ${ }^{77}$ Das Vertragsdatum ist verzerrt, deswegen entstanden verschiedene Interpretationen; m. E. haben diejenigen Historiker recht, die diese Verhandlungen auf die Jahre 1383-1384 datieren. Diese Interpretation wird durch eine Reihe von Umständen bestätigt. Gerade damals war die Lage Litauens besonders kritisch - Jogaila führte gegen Witold und den Deutschen Orden einen Krieg; und gerade in dieser Zeit begab sich Bischof Dionisij von Suzdal nach Konstantinopel, offensichtlich als der gemeinsame Kandidat Litauens und Moskaus für den Metropolitenstuhl (es gab damals zwei Metropoliten - Pimen in Moskau und Kiprian in Litauen). Aber kurz danach gab Jogaila diese Pläne auf, und Dionisij wurde durch den orthodoxen Fürsten Wladimir Olgerdovič von Kiew verhaftet und starb in Gefängnis. ${ }^{78}$ Das wäre aber eigentlich keine litauische Alternative, weil Jogaila keine führende Rolle in diesem Bündnis gehabt hätte. Laut dem Regest des Vertrages versprach er, „im Willen Dmitrijs“ zu sein; unter anderem handelte es sich um die orthodoxe Taufe Jogailas und seiner Untertanen.

75 Idem: Annales seu Cronicae incliti Regni Poloniae. Lib. XI (1413-1430). Varsaviae 2000, S. 219-220, 243-246.

76 Кром, М. М.: Меж Русъю и Литвой, S. 43-118.

77 Описъ архива Посольского приказа 1626 года. Ч. 1. Москва 1977, S. 34-35. Früher ediert in Auszug: ДДГ, S. 460-461. Zur Datierung der opis'vgl. Кучкин, В. А.: Договорные грамоты, S. 119, Anm. 3.

78 Флоря, Борис Н.: Договор Дмитрия Донского с Ягайло и иерковная жизнь Восточной Европь. Неисчерпаемость источника. К 70-летию В. А. Кучкина. Москва 2005, S. 233-237; TЕ̨Gowski, Jan: W sprawie genezy unii Polski z Litwa. Projekt matzeństwa Jagietty z córka Dymitra Dońskiego wielkiego księcia moskiewskiego - próba ustalenia daty. Prace Naukowe Akademii im. Jana Długosza w Częstochowie. Seria Zeszyty Historyczne 2009, Zesz. 10, S. 51-64. Die Argumente der Forscher, die die Abschließung dieses Vertrages mit einer anderen Zeit verbinden oder gar leugnen, sind nicht überzeugend. Unter anderem verweisen sie auf das Wort svat (etwa Schwager) in den Regesten anderer in der opis verzeichneter Verträge, mit dem die Beziehung zwischen Dmitrij von Moskau und Olgerd sowie zwischen Wladimir Andreevič und Olgerd mit seinem Bruder Kinstutt (Kęstutis) charakterisiert wird (Лицкевич, Олег В.: Православное крещение Ягайло и проект литовско-московского династического союза 1376-1377 г2. In: Інтәграцыйныя працэсы ў гісторыі краін Усходняй Еўропы: Матәрыялы Міжнароднай навуковай канферәнцыі, Мінск, 19-20 лістапада 2008 г. Мінск 2008, S. 131-147, hier S. 141; BARonAS, D. - Rowell, S. C.: The Conversion of Lithuania, S. 249-256, hier S. 253). Diese Bezeichnung ist im Kontext der damaligen Vorstellungen jedoch ganz logisch: Dmitrij erscheint hier als das Oberhaupt des Moskauer Riurikidenzweiges, der zur Schließung der Ehe zwischen Wladimir und der Tocher Olgerds beitrug (siehe dazu: ЛитвинА, Анна Ф. - УСпенский, Фёдор Б.: К уточнению семантики древнерусского «свататися» / «сватитися» и «сват(ъ)ство» (Историко-филологический этюд). Die Welt der Slaven 58, 2013, S. 308-325). 
Diese Bemerkungen führen zu folgendem Schluss: Es gibt keine Gründe, von der „litauischen Alternative für die ganze Rus'“ zu sprechen. Die litauischen Herrscher setzten sich nicht zum Ziel, das ganze „Kiewer Erbe“ unter ihrer Macht zu vereinigen, sondern verfolgten die Entwicklungen in dieser riesigen Region Osteuropas und erweiterten ihren Machtbereich entsprechend. Litauens Ansprüche gestalteten sich situativ und erreichten nie eine ähnliche Breite, wie die Ansprüche der Moskauer Fürsten seit dem letzten Viertel des 15. Jahrhunderts; es ist abwegig, auch den Gediminiden solche Ambitionen zuzuschreiben. Als sie mit den Staaten der nord-östlichen und nord-westlichen Rus' zusammenstießen, waren diese schon ziemlich hochentwickelt und von innen konsolidiert. Ihre Unterwerfung wäre mit sehr ernsthaften praktischen Problemen verbunden. Es ist auch zweifelhaft, dass die „dynastische Union“ zwischen Moskau und Litauen, wenn der Vertrag Jogailas mit Dmitrij Donskoj umgesetzt würde, zur dauerhaften Vereinigung der ganzen Rus' unter einem Herrscher führen könnte. In Wirklichkeit existierte lediglich für die Grenzgebiete beider Staaten eine Alternative, und zwar Moskau oder Wilno; es ist auch berechtigt, von der „anderen Rus'“ als einem alternativen Weg der politischen, sozialen, wirtschaftlichen oder geistlichen Entwicklung zu sprechen. Man sollte nicht vergessen, dass sich die Wege der Länder von der westlichen und südlichen Rus' einerseits und der nordlichen Rus' andererseits ziemlich früh trennten.

\section{Litevská alternativa pro celou Rus? Východní politika litevských panovníků na konci středověku: postuláty a skutečnost.}

Studie reaguje na v moderní historiografii rozšířený názor, že litevské velkoknížectví údajně usilovalo o sjednocení celé Rusi pod svou vládou, a proto představovalo reálnou alternativu k politice moskevských velkoknížat. Analýza jednání a postojů litevských velkoknížat ukazuje, že po celé období expanze do ruských zemí nevznášeli nárok na celou Rus. Snaha vidět takové nároky v určitých momentech při jednáních s posly Karla IV. v roce 1358 nebo údajně v předvečer bitvy na Vorskle v roce 1399 je nepodložená. Autor dokládá, že Olgerd, Jagello a Vitold neměli reálnou šanci podmanit si moskevské velkoknížectví, jeho spojence a vazaly ani pomocí vojenských výprav (1368-1372, 1406-1408) a ani prostřednictvím manželských svazků s moskevskými Rurikovci (1383/84). 